\title{
In Memoriam Charles Henry Peterson
}

Charles 'Pete' Peterson passed away on October 24, 2020 at his home in Pine Knowles Shores, North Carolina, USA. Pete was an exceptionally creative and productive scientist, who made many important contributions to ecology and marine science. He obtained a BA in Biology at Princeton University in 1968 before receiving an MS in Zoology (1970) and a PhD in Biology (1972) working with Joe Connell at the University of

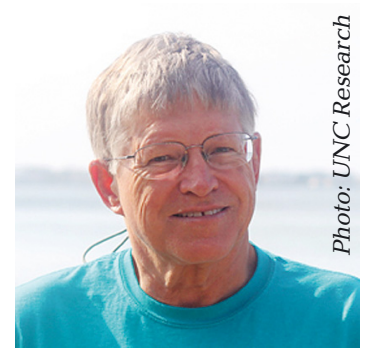

Pete Peterson (1946-2020) resulted in him recognizing that restoring scallop populations decimated by red tides in coastal North Carolina was critical to local fishers while also providing novel insights into larval connectivity and recruitment limitation. His many contributions to marine conservation were widely recognized and awarded, such as with a Pew Fellowship and other prizes.

Pete spent a large proportion of his career actively shaping policy and engaging in management on a range of environmental issues. While Pete served on numerous international and national advisory committees, including with ICES (International Council for the Exploration of the Sea), GLOBEC (Global Ocean Ecosystem Dynamics), NSF (National Science Foundation), and NCEAS (National Center for Ecological Analysis \& Synthesis), he was equally proud of his work on the North Carolina Environmental Management Commission, just one of the several environmental commissions in the state that Pete served on over the past several decades. North Carolina's coastal habitats and resources are more resilient thanks to Pete's tireless efforts and dedication.

Above all, Pete was an educator and mentor. His ability to articulate difficult concepts in the classroom and in the field coupled with his enthusiasm for teaching inspired and enabled many to pursue careers in marine ecology. Pete left behind a large network of former students, post-docs, and colleagues whose careers he helped shape. At his retirement party in 2019, many of these recounted with gratitude how Pete made them stronger scientists through demanding the level of scientific rigor, clarity, and excellence that he consistently delivered in return. He will be greatly missed.

\section{Hunter S. Lenihan*}

Bren School of Environmental Science and Management, University of California — Santa Barbara, Santa Barbara, CA 93106, USA

\section{Jonathan Grabowski**}

Marine Science Center, Northeastern University, Nahant, MA 01908, USA tices and management strategies. He highlighted that oil spilled by the 'Exxon Valdez' triggered a cascade of long-lasting ecological effects throughout Prince William Sound, thus transforming our understanding of oil spill impacts. Pete's exceptional capacity to integrate and synthesize ideas across disciplines

\section{Fiorenza Micheli ${ }^{* * *}$}

Hopkins Marine Station and Stanford Center for Ocean Solutions, Stanford University, Pacific Grove, CA 93950, USA 